\title{
Challenge or Chaos: A Discourse Analysis of Women's Perceptions of the Culture of Change in the IT Industry
}

\author{
Sue H. Nielsen, Liisa A. von Hellens, and Jenine Beekhuyzen \\ Griffith University, Brisbane, Australia
}

\author{
s.nielsen@griffith.edu.au I.vonhellens@griffith.edu.au \\ i.beekhuyzen@griffith.edu.au
}

\begin{abstract}
An ongoing investigation into the declining participation of women in IT education and professional level work has recently focused on professional women's perceptions of the IT industry. This paper presents some of the findings from a discourse analysis of interviews with thirty-two female and two male IT professionals. The analysis identified a distinctive characteristic of the women's discourse in the representation of mutually exclusive attributes, skills and attitudes as closely identified with gender. This paper explores two of these dualisms - women's perceptions of the rapid and continuous change characteristic of the IT industry and the dualism of the public (work) and private (domestic) spheres. The implications of rapid change and the concomitant long working hours characteristic of the IT industry, are discussed in relation to women's continued responsibility for social and domestic life. Discourse analysis is used to identify contradictions in the women's talk and to relate this to tensions in the IT industry and the wider social context. Although these women characterise themselves as 'different' from most women, in their skills, aptitudes and attitudes towards IT, this characterisation shows tensions and contradictions. The authors use Giddens' perspective on identity formation and the structuration of institutions (Giddens, 1984; 1991) to identify factors, which may further discourage women from participating in IT education and work.
\end{abstract}

Keywords: gender and IT, structuration theory, discourse analysis

\section{Introduction}

The IT industry is one of the most significant for any modern industrial state, in terms of supporting domestic services, enabling a nation to engage in global communications and providing opportunities for international trade. However, the supply of personnel to this industry remains problematical, with a long-term decline in the supply of high achieving students, particularly female students. More recently, in response to the dot.com crashes, the decline has been more significant (Throp, 2003), despite a considerable revival in job opportunities, which show that IT is still one of the most significant employment sectors, particularly for graduates (Foreshew, 2003).

Material published as part of this journal, either on-line or in print, is copyrighted by Informing Science. Permission to make digital or paper copy of part or all of these works for personal or classroom use is granted without fee provided that the copies are not made or distributed for profit or commercial advantage AND that copies 1) bear this notice in full and 2) give the full citation on the first page. It is permissible to abstract these works so long as credit is given. To copy in all other cases or to republish or to post on a server or to redistribute to lists requires specific permission from the publisher at Publisher@InformingScience.org
The new enrollments are down by thirty per cent or more in some IT courses in Australia (Throp, 2003) an according to the study by University of Melbourne's Centre for the Study of Higher Education that was commissioned in 2002 by the Education Minister Brendan Nelson women in engi- 
neering and information technology are still regarded as an equity group - with targets of 40 per cent or more participation unmet (Illing, 2004).

This paper reports on the latest findings of a research project into women in information technology. The WinIT project, commenced in 1995 has taken a multi-dimensional approach to the complex problem of declining female participation (von Hellens \& Nielsen, 2001). This paper builds on recent work, which explores the career satisfaction of professional women in the IT industry.

A discourse analysis of the interviews with professional IT women revealed a distinctive discursive practice in the women's discourse; that is the representation of what we term 'dualisms' mutually exclusive attributes, skills and attitudes as closely identified with gender (Beekhuyzen, Nielsen \& von Hellens, 2003; Nielsen, von Hellens, Beekhuyzen \& Trauth, 2003). These dualisms include reification of skills necessary for IT work, into 'hard' and 'soft', with skills such as programming and technical skills viewed as completely different from management, business and communication skills. This paper explores two of these dualisms - the aptitude and skill with which women cope with rapid and continuous change in the IT industry and the dualism of the public (work) and private (domestic) spheres.

Giddens' notion of identity links the formation of personal identity to the characteristics of modern institutions and is concerned with "the emergence of new mechanisms of self-identity which are shaped by - yet also shape - the institutions of modernity" (Giddens, 1991, p.2). In this paper we explore how women represent their identities in masculinised domains - IT work and academia - and how the challenges to identity formation may partly explain why IT work does not attract more female participation and may even alienate some men.

This paper aims to contribute to the ongoing research into the nature of female participation in professional level IT education and work, by exploring the relationship between gender and information technology, especially in relation to the rapidly changing nature of the industry and its impact on the domestic and work spheres in which women are expected to actively participate. We have indicated in previous papers that the women's discourse shows several contradictions (Beekhuyzen et al., 2003; Nielsen et al., 2003; von Hellens, Nielsen \& Beekhuyzen, 2004), and in this paper we wish to explore contradictions in their discourse about coping with the rapid change in the IT industry, and the implications for recruiting and retaining women in the IT industry.

\section{Research Approach}

Research into gender and IT has taken two major approaches; that men and women are inherently different or that gender differences are primarily socially constructed. The inherent differences approach comprises two streams of research. The first looks at gender differences in the acceptance of technology. For example, Venkatesh and Morris (2000) and Venkatesh, Morris \& Ackerman (2000) investigate gender differences in computer anxiety and aptitude, concluding that these differences explain lower adoption rates by women. A similar approach is taken in studies of female students, which treat women as an undifferentiated category and focus on the psychological characteristics that restrict, rather than encourage, them to undertake IT studies (Brosnan \& Davidson, 1996).

A second stream of research within the inherent differences approach is represented by Spender (1995) who holds that increased female participation in the IT industry would transform and improve information technology design and use.

Our approach in the WinIT project views gender and technology as socially constructed and seeks to explore the masculinisation of the IT domain and the way that women cope with the social embededness of IT institutions. This does not imply that women may be treated as an undifferentiated category. Recently Trauth (2002) discussed research, which critiques the social construction 
perspective (e.g. Wajcman 1991) pointing out that "there is no behaviour or meaning which is universally and cross-culturally associated with either masculinity or femininity" (2002, p.102). Furthermore, Trauth (2002) explored the way that an individual woman responds "to the way the IT profession is socially constructed as a male domain in her particular experience".

This paper explores a similar theme by considering how women construct themselves as 'different' in order to cope with the dualisms of rapid change and the private/public spheres of operation. In this way we can begin to explore how individuals may construct, maintain and transform an institution such as the IT industry. Giddens' theory of structuration (1984) has been used as a meta-theory to guide our understanding of the relationship between the individual and social institutions. In this paper we focus on the culture of change in the IT industry, by examining instances of the interviewees' discourse, to "understand both the system that structures the whole way of life and the ways of living that people devise within it" (Fiske, 1998, p.371)

\section{Data Collection and Analysis}

Interviews were conducted with thirty-two (32) female and two (2) male IT professionals working in Australia. The data collection was a collaborative effort between two Australian-based researchers and one US-based researcher.

The interviewees represent a range of ages, employment sectors, educational backgrounds and ethnic backgrounds. The males were interviewed primarily to provide insight into the female experience. The men's comments provided a further point of reference and helped us to position the female comments in the broader context of the Australian IT industry. They served as experts, perceptive meta-level observers of the industry including its work practices, its skills and its values regarding women (von Hellens, Nielsen \& Trauth, 2001).

Semi-structured open-ended interviews of approximately 90 minutes in duration allowed interviewees to express their personal views and discuss their individual experiences in the Australian IT industry. Four main areas were covered, including demographic information, personal history, general questions about gender and IT, and recommendations regarding how society, the IT profession and educational institutions might address the gender imbalance in IT. The interviewed women are not a random sample, they were gathered primarily from 'Women in Technology' (WIT), an industry organisation for women IT professionals who has a mission to sustain an active network of women in the IT industry, facilitating career development and promoting enhanced industry management in Brisbane, Australia. These women are both the subjects of our study and informed observers of the skills issues faced by women in the industry. As mentioned above, this study does not consider the observed skills required by women in the industry such as Todd, McKeen \& Gallupe (1995), instead it explores the perceived perceptions of these women.

The respondents were IT practitioners working in a range of levels at a range of industries in various parts of Australia and academics in IT faculties. The respondents drew upon their own experiences to offer insights about the themes, which were explored in this study. The female subjects offered two perspectives on the topic; their experiences of entering and progressing in the IT field, and helping other women enter and succeed in IT.

The third author carried out the initial sorting and analysis of the interview data with the aid of NUD*IST, an Australian qualitative software application. NUD*IST is an acronym for Nonnumerical Unstructured Data, Indexing, Searching and Theorising and is designed to aid users in handling Non-numerical and Unstructured Data in qualitative analysis, by 'supporting processes of coding data in an Index system, Searching text or searching patterns of coding and Theorising about the data'. The advantages and limitations of using this software within this context are discussed in Beekhuyzen et al., (2003). 
This paper revisits the interview data discussed in previous papers (Pringle, von Hellens, Nielsen, Greenhill \& Parfitt, 2000; Trauth, Nielsen \& von Hellens, 2003; von Hellens, et al., 2001) from the perspective of the relationship between gender and IT, focusing on change as a defining characteristic of the IT industry.

\section{Discourse Analysis}

The study has used a text-oriented approach to discourse analysis based on the work of Fairclough $(1992,1997)$ to make explicit the interpretation of the discourse within the wider social and institutional context. In the last decade there has been an increased interest in the use of discourse analysis in information systems research, as exemplified by the 2002 IFIP TC8/WG9.2 conference. This conference addressed key concerns of discourse analysis, such as "What assumptions are hidden in our talk about plans for change?" and "What forms of discourse mask or create confusion, rather than clarifying issues?" (Wynn, Whitley \& Myers, 2002). Our current research addresses similar concerns, attempting to identify contradictions in the relations between gender and information technology.

In gender studies, discourse analysis has been used to identify the differences between male and female discourse and the way power is associated with male discourse (Halford and Leonard, 2001, p.74). While such a study in IT would be very informative, our objective is somewhat different - to identify discursive practices in female discourse which maintain or challenge the masculinised domains of IT education and work.

The diagram below shows a conceptualisation of the framework for analysis and interpretation.

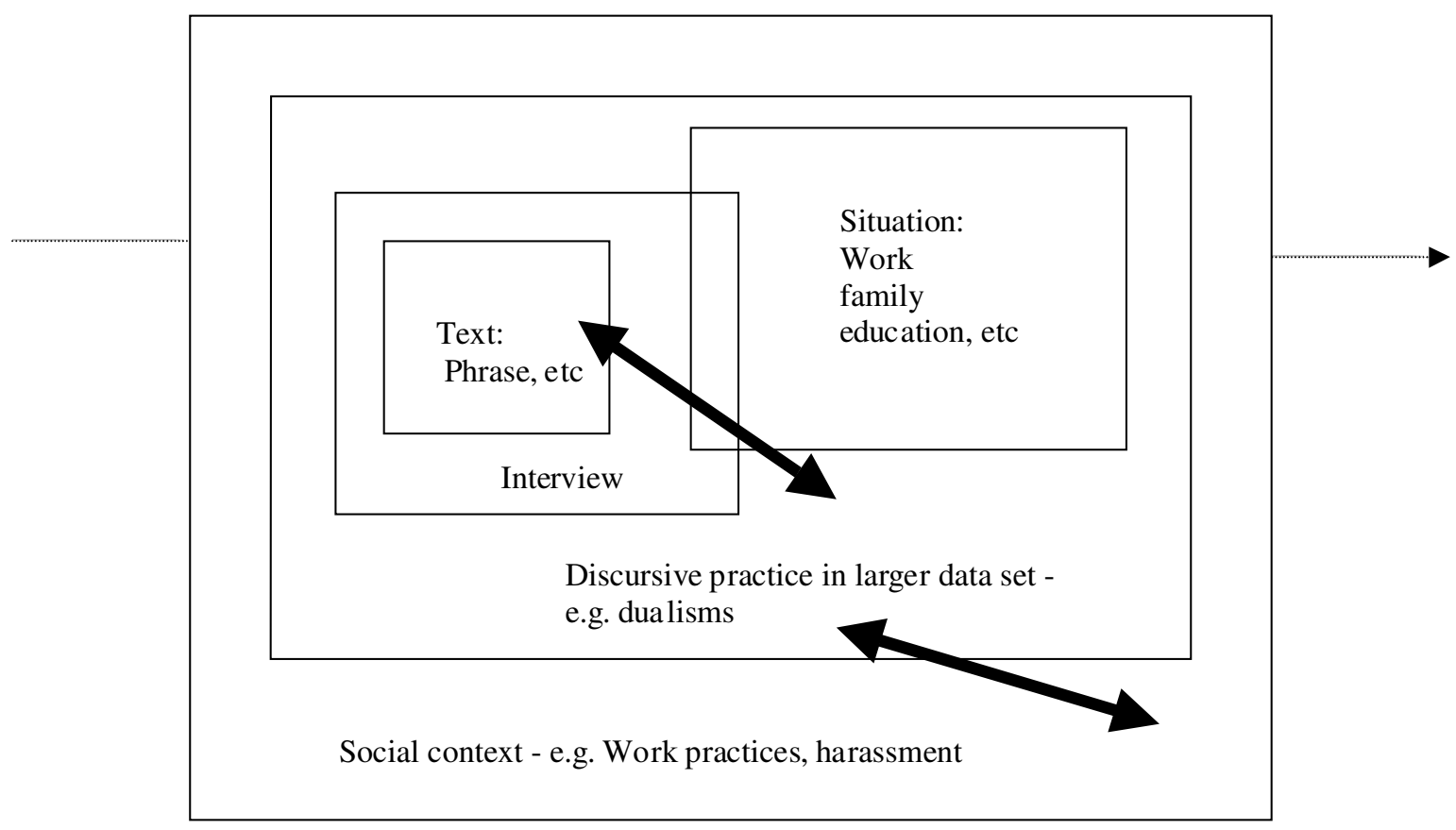

Figure 1 Conception of framework for analysis and interpretation (adapted from Fairclough, 1992)

By text, we mean a particular instance of discourse, ranging from a short phrase to an extended answer to an interview question. This text is considered within its immediate discursive context, 
which for this research study is the entire interview. The interpretive focus widens (indicated by the arrows) by taking into account the situation, which the speaker is referring to, such as event in the workplace. We widen our focus further by then looking at the relationship of these elements to distinctive discursive practices (patterns of expression) across the whole data set, such as the use of dualisms (Nielsen et al., 2003).

Our interpretation is based not only on our examination of the interview data but also on our reference to the wider context, sourced from our experiences, those of other women we have interviewed and indeed the research literature on women in IT. For this research study we have conceptualised this wider context, as socially constructed, using structuration theory as a meta-theory to guide our interpretation of the meaning of the discourse. The interpretation is iterative, as indicated by the double-headed arrows. That is, we look for consistency, coherence and contradictions between the text, situation and wider social context. The ongoing nature of structuration is reflected in our approach to analysis, with the broken arrows indicating that interpretation takes into account the history of the situation as well as expectations about likely future events.

This framework enables us to not take the discourse at face value but to consider the range of meanings intended by the speaker; in other words we are interested not only in what the discourse denotes but also by the range of connotations.

Macey explains denotation and connotation quite simply as follows; "a word denotes primary or dictionary meaning but also connotes a whole set of associated meanings" (2000, p.91). Hence the interpretive act may be viewed as an endeavour to discover all the relevant connotations of a text, and this requires attention to the context - textual, situational, social, cultural, organisational and/or institutional. The figure below illustrates the possible range of meanings intended by an interviewee who characterised her work in the IT industry as the need "to keep learning and never stop" (Cynthia, 332-8). Please note that the names have been changed to pseudonyms to protect the identity of the interviewees.

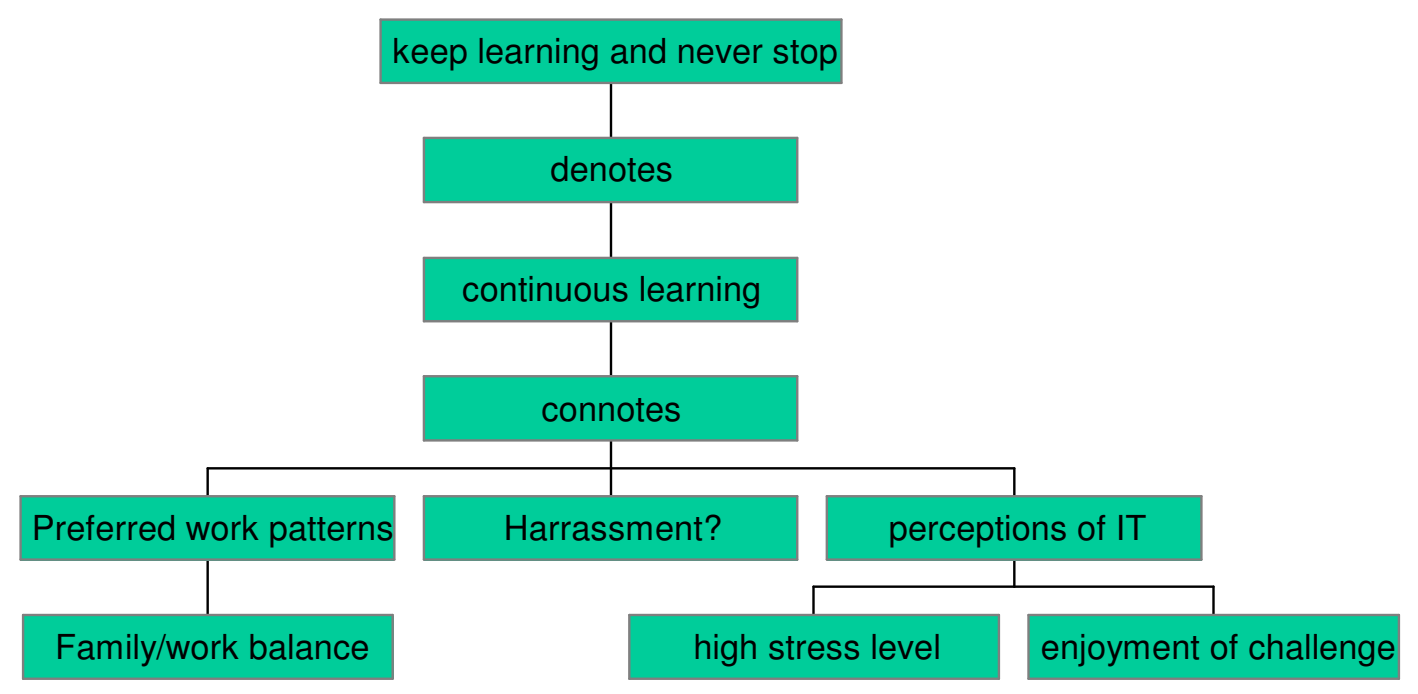

Figure 2 Denotation and Connotation

In order to interpret the discourse, reference must be made to other statements made in the interview, as well as the current context of IT work. In this case, repeated expressions of this type enabled us to consider the dualism of change as challenge or chaos as well as the dualism of work and family in the modern IT work experience, which we explore further in this paper. 


\section{The Challenge of Change}

A recurring theme in the interviews is that the women perceive themselves as different in their response to rapid technological change and innovation. "So in that way you're really different because most people don't like change" (Geraldine, 175). Moreover, they identify this attribute as usually associated with men. "What makes me different .. knowing about new things which aren't traditionally for women... being able to go around in that area which has been long reserved for men" (Kylie, 176).

In most cases, it is this challenge of change is something which attracts them to the IT industry. "I like being part of it [change], you're really in the problem industry when you are in computing" (April, 51).

The disadvantages are also clearly stated by these women, most obviously the long working hours, "In answer to the question is it necessary to do such long hours "yes - companies just expect so much more from their employees" (Faye, 93).

They also acknowledge the potential for burnout, "It's a continuing challenge though it can be really tiring [rapid rate of tech change] (Sharon, 120). "Long hours, chained to your computer all the time. Pressure to meet deadlines. A bit of me is burned out by it" (Claire, 352).

All of the women experienced difficulties in maintaining a reasonable private life, "Sometimes things get critical and you can't just leave things as is. You have to finish everything before you go off. So that kind of cuts into your social life. Sometimes I say to my fiancé to come at 5 to meet me and then I can't leave because I have to finish things off" (Kylie, 116).

Some of the women interviewed were apprehensive about their ability to combine motherhood with this type of career. "And as I look forward to getting married and having children I don't want to give up my job and I'm very fearful of how employers will view me going through maternity. I' $m$ also concerned with the fact that I look after the bills and I look after the house. I don't know why that is but I end up doing that. And when the children come along, I'm not sure how I'm going to cope with that and an all-consuming job. And yet I don't want to work in a job that is not all-consuming because I won't find that satisfying" (Faye, 93).

They were also concerned with the problem of taking time off from work, when they might fall behind. "It's fear, fear of being left behind, in such a fast changing environment" (Sharon, 108). This apprehension is supported by Australian data which shows that women with children earn less than their childless counterparts (Megalogenis, 2003).

Overall, the women saw IT as a career which did not easily accommodate women's traditional domestic responsibilities and aspirations. "The way IT is structured right now, it is very much a young, unencumbered person's career" (Sue, 188). This is in keeping with research by Gallivan (2003) which found that "women's perceptions of being stressed/overworked were positively associated with the total amount of change in the workplace, but for men there was no such relationship" (Gallivan, 2003, p.19). As a result, the women interviewed indicated that the IT industry was a domain where women are "not accepted very well" (Geraldine, 181).

Overall, the discourse about the challenge of change shows the tension between the enjoyment women experience in an environment where continuous learning and problem solving are the norm, and the difficulties of managing the long hours and domestic aspirations. Some of the interviewees mentioned the possibility of burnout. One older female software engineer stated that she would not encourage her daughter to take up IT as a career because "it is too difficult for a girl...you have to keep learning and never stop .. too difficult to keep up with the work and take care of the family" (Cynthia, 332-8). 
Our earlier studies of high school students (Greenhill, von Hellens, Nielsen \& Pringle, 1997) also indicated that many students observing the work patterns of their parents are discouraged from entering an industry where stress levels are very high.

Since many IT professionals also remember their IT studies as being difficult and challenging, this may also provide a negative image to their potential students. "It was very difficult to do computer science compared with the core science subjects. We'd see the maths students playing cards in their tutorials sessions .. we'd have to work all night" (April, 14).

\section{Challenge or Chaos?}

As discussed above, the women interviewed all mentioned the rapidly changing technology as one of the things which attracted them to IT work. However, many of them were critical about the type of changes, which they were expected to cope with. "They always try to stay one ahead of what their competitor is doing in IT. It's almost a bit like schoolyard politics - I want to be better than they are. All the people who don't know how to turn on a PC are suddenly asking their IT department - oh do we have one of those web site things because Joe Blow's company over here does" (Sharon, 48).

They also challenged the need to work such long hours, "Even in technical roles ... you can deliver to a time frame without having to work more than full-time, which is what most companies seem to demand of their employees" (Barbara, 65).

Sometimes, the need to keep up is seen as having negative impacts on the clients, "And the reality is I do $20 \%$ of my job really well and I let a lot of people down every day of the week and that's been hard personally to cope with" (Faye, 93).

This may be related to the widespread discussion of the importance of 'soft' skills and the reported tendency of women to see the application of technology as more important than mere innovation. Making sure that the technology works and delivers on its promises is more important than devising new technologies to provide new types of products or services. In that regard their thinking is in line with current business ideas regarding the need for information technology to show a return on investment, rather than continuously providing new services. For example, in a recent Australian IT Newspaper forum, an IBM executive stated "the value of the technology is in the application, not the invention" (Hayes, 2003, p.36). In the same forum, a top banking executive also emphasised that IT needed to focus on providing immediate payoffs rather than delivering new products (Gottliebsen, 2003, p.35)

The impact of continuous change on career paths and job security is also seen as potentially negative. Some IT companies do not bother to retrain staff, with employees becoming lost to the industry. "Usually they get rid of the old staff and employ new staff. They don't take the time to train [staff]" (Sharon, 95).

This may lead to high job turnover, "So young technical people are not feeling loyal to one company - [they] just want to grab a skill at each job and focus on their personal career rather than being loyal to the progress of a firm" (April, 153).

As discussed in previous papers (Nielsen, et al., 2003, von Hellens, et. al., 2003) much of the women's discourse could be viewed as an attempt to achieve what Giddens calls 'ontological security'. This is achieved through the making sense of routine activities by framing them within a 'natural' sense of the way things are. However, when people start to challenge the appropriateness of their own actions (such as their ability to provide satisfactory service to the majority of their customers) as well as institutional arrangements (such as unreasonable working hours and the management of change), their self-identity as well as their trust in institutions is challenged. 
Their shared framework of reality is threatened. "On the other side of what appear to be quite trivial aspects of day-to-day action and discourse, chaos lurks" (Giddens, 1991, p.36).

\section{Career or Children?}

In an earlier paper (von Hellens, Nielsen \& Beekhuyzen, 2003) we identified the separation of home and work as a recurring dualism in the interview discourse. The fact that men have not taken up their share of domestic work, including the raising of children, despite the increased participation of women in the workforce, has now been so widely discussed that the women interviewed do not refer it to explicitly. However, it is implied by statements such as "I'm also concerned with the fact that I look after the bills and I look after the house. I don't know why that is but I end up doing that. And when the children come along, I'm not sure how I'm going to cope with that and an all-consuming job" (Faye, 93).

Continuous learning and rapid change were associated with the masculinisation of the industry in that the women interviewed saw it as a characteristic of IT work which men were better equipped to deal with. Keeping up with rapid change was a significant part of the need to work very long hours, which subtly discriminates against women who take greater responsibility for domestic work and the care of children. There is no doubt that the IT industry is not alone in its increasingly rapid rate of what Gleick (1999) calls "fast cycle time" (p.75) but this may be an alienating factor for women who wish to balance their private and work lives. In particular, the fear of losing ground if they take time off to have children may inhibit women from entering the IT industry or cause them to leave.

According to Martin (2002), organisational theorists usually take the position that the domains of work and home are separate, and that this may suit individuals who desire privacy and autonomy. "Companies too have a reason for reifying this separation: for example if an employee encounters difficulties at home ... those problems are the responsibility of the individual and not the company" (Martin 2002, p.357). However, as Martin goes on to say, the private and public spheres are inextricably related; the requirement to work unusually long hours will affect personal life and difficulties at home will impact on an employee's performance at work. For example, the women interviewed indicated that handling their emotions was a significant problem in adapting to a male work environment. "Trying to manage your emotions is very difficult. I don't know about the drop out rate of women in IT. But being a male that is unacceptable. And it is very difficult to learn that skill of managing your emotions to the point where that just doesn't happen and you are able to talk the language that men talk in business" (April, 15).

The application of information technology gave an early promise that this separation of home and work is not necessarily immutable. However, the persistent view that work and home can and should be separated may continue to alienate women from mainstream IT education and careers.

\section{Different or Differentiating?}

To interpret these findings we consider women's discourse as one of the strategies for identity formation. The women interviewed represented themselves as different from other women in their interest in the 'male' domain of rapid technological change, but also different from men in their critique of IT change. In this regard they saw their feminine attributes as contributing something unique (different from men) and important, to the IT industry. "I actually think that women will be able to humanise IT by being involved in it but you've got to speak the language before you involve them otherwise you turn them off" (April, 15).

Another contradiction appeared strongly in the interviews, which the women did not attempt to explain. That is, although they perceived themselves as different from most women, as operating 
confidently in a domain where women are "not accepted very well" (Geraldine, 181), they also suggested strongly, that if more women understood the diverse nature of IT work, a greater number of women would take up IT careers. They did not suggest that these other women were also 'different'. Instead, some of their discourse suggests that these women would fit into the more non-technical areas of the IT industry. "They (women) don't understand, they think programming is all there is to IT. That's not right. They don't have to know how to pull a machine apart... There are dozens of other jobs in IT that don't need that" (Diane 84).

This contradiction also relates to the difficulty of defining the IT industry. However, what we consider important is that these women saw themselves as occupying a unique position, different from traditional male and female roles. "A self-identity has to be created against a backdrop of shifting experiences of day-to day life and the fragmenting tendencies of modern institutions" (Giddens, 1991, p.186). The fact that many of them were concerned about burnout and were apprehensive about their ability to balance their work and private lives indicates that even these 'new' women may not continue to be attracted to or retained by the IT industry.

\section{Conclusion}

Our analysis of the discourse relating to the challenge of change revealed several contradictions, as discussed above. If we interpret this discourse within its immediate situational context (Fairclough 1992), we must acknowledge that these women are being invited to give accounts of themselves, their work and their perceptions of the IT industry. Such studies therefore involve what Giddens (1984, p.374) calls the 'double hermeneutic', in which there is constant 'slippage' between the world constituted by the those who act in it and the reflections on that world, constructed not only by the analyst but by the reflective practitioner. Such talk therefore inevitably comprises contradictory themes, which reflect participants' need to make sense of routine activities and to resolve dilemmas in their sense of identity.

The women interviewed did not attempt (and were not invited to try) to consider the meaning of the contradictions in their discourse. However, such contradictions between the discursive and social practice - what Fairclough calls the "forms and content" (Fairclough, 1992, p.222) - indicate that a struggle is taking place between what women can express about their work and their everyday experiences. This sense of struggle becomes explicit when women acknowledge their difficulties in adapting to the IT industry as it is presently constituted.

Dealing with the rapid rate of change by identifying oneself as different from the majority of females, gender may be a means of coping with what Giddens (1991) calls the crisis prone nature of modernity. Indeed the characterisation of the IT workplace as an arena of continuous problem solving where employees cannot hope to provide good solutions to most of their clients indicates that the IT industry is crisis ridden. In this respect the IT industry is a modern institution and according to Giddens this could have two implications; it "fuels a general climate of uncertainty' and exposes people to crisis situations "which may sometimes threaten the very core of selfidentity" (1991,p.184).

This paper suggests that the women interviewed are struggling to find a way to express their identity and that this is most distinctively shown in their conceptualisation of their 'difference' particularly with regard to their ability to cope with change. Giddens describes the fragility of modern institutions in terms of the burdens they place on their employees. "In the reflexive project of the self, the narrative of self-identity is inherently fragile. The task of forging a distinct identity may be able to deliver distinct psychological gains but it is clearly also a burden (Giddens 1991, p.185-186). Our interpretation of the interview data suggests that the formation of the female identity in the IT industry is still incomplete and subject to contradictions. 
The difficulty of attracting and keeping expert personnel in an industry which one of the interviewees regards as suitable only for the "unencumbered young" (Sue, 188) will increase as the baby boom generation retires "creating a hole in the upper levels of all industries" (Throp 2003, p.29). This is particularly significant when we consider the increasing participation of women in the workforce. A decade ago, Jonung and Persson (1993) pointed out that with the general decrease in jobs for men and the steady rise in single parent families, the issue of gender has become crucial for understanding the direction that institutions and organisation will take in the $21^{\text {st }}$ century. Recent research indicates that in Australia at least, women now make up 53\% of the nation's professional workforce and 63\% of the current tertiary graduates (Megalogenis, 2003, p22).

In this paper, we have examined one set of contradictions in women's discourse about IT work. By relating the contradictions in the discourse to the wider institutional and social context, we hope to illuminate not only the issue of the declining participation of women in the IT industry, but also the problems that the industry may face in recreating and sustaining itself in the $21^{\text {st }}$ century. The women interviewed believe that they have a unique contribution to make but their satisfaction with their work is undermined by the culture of change in the IT industry.

To map this culture would require considerable study. However this paper suggests some of its features, of which women are critical; technological change for its own sake, without regard to the benefit for stakeholders, including the inability to solve the majority of clients' problems; the assumption that long working hours are required to achieve satisfactory outcomes; the difficulty of reconciling a reasonable private life with the requirements of a satisfactory career. As confirmed by the male interviews, these are not problems unique to women and they may be a factor in the inability of traditional IT courses to attract high achieving male students as well.

As far as future study suggestions are concerned, a parallel study of male IT professionals might help focus attention to the negative aspects of the IT workplace mentioned by many of the interviewees and indicated as being equally difficult for males. If a workplace structure is purposely made more difficult and competitive for all workers, favouring single, uncommitted people generally and that all workers are negatively affected by workplace conventions, the way forward is to target exploitative employers and bosses, rather than to divide along gender lines, diverting attention away from the employers.

\section{Acknowledgements}

The authors gratefully acknowledge financial support from the Australian Research Council Large Grants scheme, which funded the collection of the interview data by the first two authors and Professor Eileen Trauth. The authors thank Professor Trauth for her collaboration with the WinIT project and for allowing access to her interview data. The authors also thank the two anonymous reviewers who raised many important issues for this research that are unable to be discussed in a paper of this length. These issues will be followed up in future research.

\section{References}

Beekhuyzen, J. P., Nielsen, S. H. \& von Hellens, L. A. (2003). Challenging the dualisms in female perceptions of IT work. The Australian Journal of Information Systems, 10 (2), 105-114. Also in Proceedings of AusWIT03; Conference on Australian Women in IT

Brosnan, M.J. \& Davidson, M.J. (1996). Psychological gender issues in computing. Gender, Work and Organization, 3 (1), 13-25.

Crystal, D. (1987). The Cambridge encyclopedia of language. Cambridge: Cambridge University Press. 
Greenhill, A., von Hellens, L.A., Nielsen, S.H. \& Pringle, R. (1997). Australian Women in IT Education: Multiple Meanings and Multiculturalism. Proceedings of the 6th International IFIP Conference on Women Work and Computerization (WWC 1997), Bonn, Germany, 26-28 May 1997, pp.387-397.

Fairclough, N. (1992). Discourse and social change. Cambridge: Polity Press.

Fairclough, N. (1997). Conversationalization of public discourse and the consumer. In R. Keat, N. Whiteley, \& N. Abercrombie (Eds.), The authority of the consumer (pp. 253- 268). London: Routledge.

Fiske, J. (1998). Audiencing: Cultural practice and cultural studies. In N. K.Denzin and Y. S.Lincoln (Eds.), The landscape of qualitative research: Theories and issues. Thousand Oaks: Sage Publications, pp.359-378.

Foreshew, J. (2003, December 9). Bounce in online job ads bucks the trend. Australian: IT Today, p.33.

Gallivan, M. (2003). Examining gender differences in IT professionals' perceptions of job stress in response to technological change. Proceedings of the 2003 ACM SIGMIS CPR Conference, April 10-12, 2003, pp.10-23.

Giddens, A. (1984). The constitution of society: Outline of the theory of structuration. Cambridge: Polity Press.

Giddens, A. (1991). Modernity and self-identity: Self and society in the late modern age. Cambridge, Polity Press.

Gleick, J. (1999). Faster: The acceleration of just about everything. London: Little, Brown and Company.

Gottliebsen, R. (2003, November 26). Murray chides IT leaders to catch up with the times. The Australian, pp.35-36.

Halford, S. \& Leonard, P. (2001). Gender. Power and organizations. New York: Palgrave.

Hayes, S. (2003, November 26). The Australian IT Forum. The Australian Newspaper, p.36.

Illing, D. (2004, March 3). Men emerge as equity's fall guys. The Australian Newspaper, p.29.

Jonung, C. \& Persson, I. (1993). Women and market work: the misleading tale of participation rates in international comparisons. Work, Employment and Society, 7 (2), pp.259-274.

Macey, D. (2000). The Penguin dictionary of critical theory. Penguin Books.

Martin, J. (2002). Organizational culture: Mapping the terrain. Thousand Oaks: Sage Publications.

Megalogenis, G. (2003, November 29-30). The Future Shapers. The Australian Newspaper, p.22.

Nielsen, S.H., von Hellens, L., Beekhuyzen, J. \& Trauth, E. (2003). Women talking about IT work: Duality or dualism? Proceedings of the ACM SIGCPR/SIGMIS, Philadelphia, Pennsylvania, USA, April 2003, pp.68-74.

Pringle, R., von Hellens, L.A., Nielsen, S.H., Greenhill, A. \& Parfitt, L. (2000). Net Gains: Success Strategies of Professional Women in Information Technology. Proceedings of the IFIP TC 9.1 Conference on Women, Work and Computerization: Charting a Course to the Future. Vancouver, Canada, June 2000, pp.26-33.

Spender, D. (1995). Nattering on the Net; Women, power and cyberspace. North Melbourne: Spinifex Press.

Throp, D. (2003, November 18). IT still failing to attract students. The Australian Newspaper: IT today, p.29.

Todd, P.A., McKeen, J.D. \& Gallupe, R.B. (1995). The evolution of IS job skills: A content analysis of IS job. MIS Quarterly, 19 (1), 1.

Trauth, E.M., Nielsen, S.H., \& von Hellens, L.A. (2003). Explaining the IT Gender Gap: Australian Stories for the New Millennium. Journal of Research and Practice in Information Technology, 35 (1), Febru- 
ary 2003, p.7-20. (This article is a revised and updated version of the ACIS 2000 paper, which was nominated for Best Paper.)

Trauth, E.M. (2002). Odd girl out: An individual differences perspective on women in the IT profession, Information Technology and People, 5 (2), pp.98-118.

Venkatesh, V., Morris, M.G., \& Ackerman, A.L. (2000). A longitudinal field investigation of gender differences in individual technology adoption in decision-making processes. Organizational Behavior and Human Decision Processes, 83, 33-60.

Venkatesh, V. \& Morris, M.G. (2000). Why don't men ever stop to ask for directions? Gender, social influence, and their role in technology acceptance and usage behaviour. MIS Quarterly, 24 (1), 115-140.

von Hellens, L. A. \& Nielsen, S.H. (2001). Australian women in IT. Communications of the ACM, 44 (7), pp.46-52.

von Hellens, L. A. \& Nielsen, S. H. \& Beekhuyzen, J. P. (2003). Women Working in the IT Industry: Challenges for the New Millennium. Journal of Business and Economics Research, 1 (11), 21-32.

von Hellens, L. A., Nielsen, S. H. \& Beekhuyzen, J. P. (2004). An exploration of the dualisms in the female perceptions of IT work. Journal of Information Technology Education, 3, 103-116.

von Hellens, L. A., Nielsen, S. \& Trauth, E. (2001). Breaking and entering the male domain. Women in the IT industry. Proceedings of the ACM SIGCPR Conference, San Diego, USA, April 2001, pp.116-120.

Wajcman, J. (1991). Feminism confronts technology. Polity Press.

Wynn, E., Whitley, E.A. \& Myers, M.D. (2003). Placing language in the foreground: themes and methods in information technology discourse. In E.Wynn, E.A.Whitley, M.D.Myers, and J.I DeGross (Eds.), Global and organizational discourse about information technology. IFIP TC8/WG8.2 Working Conference on Global and Organizational Discourse about Information Technology, December 12-14, 2002, Barcelona, Spain. Boston, Kluwer Academic Publishers, pp.1-12.

\section{Biography}

Sue Nielsen has taught and worked in Information Management and Information Systems for almost twenty five years and is currently a senior lecturer in the School of Computing and IT at Griffith University. As well as her involvement with Liisa von Hellens in the WinIT and mentoring projects, she has carried out research on organisational culture and employee commitment in information systems development and software quality management. Her PhD from Griffith University used ethnographic methods and discourse analysis to study change management in an information technology centre. Her current research is investigating cultural differences in perceptions of time and change in information systems development and use.

Liisa von Hellens is an Associate Professor in the School of Computing and Information Technology at Griffith University. She has over thirty years experience in the IT industry (including working as a programmer and systems developer) as well as university level education experience in Australia and Europe (Finland and UK). Her doctorate at Templeton College, Oxford University, was about packaged software provision and use, and her subsequent research, publications and consulting activities have covered information systems development and use in organisations, strategic quality management of software development, the management of IT human resources and the associated skills supply. Several refereed articles have been published on these topics. Since 1995 Liisa has also carried out research with Sue Nielsen (Griffith University) into the influence of culture and gender on perceptions of IT education and work, and the factors affecting female participation in IT education and work funded by the Australian Research Council. This research was referred to as "exemplary" by Niederman and Moore (Proceedings of the ACM SIGCPR 2000: 67-76). She is also involved in establishing an IT Mentoring Program for selected 
high schools in Brisbane, a project funded by Griffith University's Strategic Improvement Grant. Liisa also contributes to the Smart Internet Technology CRC with a current focus on E-Health.

Jenine Beekhuyzen is a Senior Research Assistant and Lecturer in the School of Computing and Information Technology (CIT) at Griffith University. After completing a Diploma of Business and an IT Honours Degree on Enterprise Resource Planning Systems and Organisational Culture, she continues to be involved in a number of research projects including the WinIT project and a Cooperative Research Centre (CRC) project on Smart Internet Technology (currently focusing on E-Health). She is currently the President of the School of Computing and IT Alumni Association and Editor of their e-zine. As well as being a mentor a number of IT Mentoring projects in Brisbane, she has also been involved in the development and commencement of a Computing and IT Alumni Mentoring program within the University that has been very successful to date. She is very active in the professional community and in encouraging girls in schools to consider a career in IT. In addition to her role at Griffith University, she works as a consultant for a small IT organisation, ThoughtWare, with a focus on knowledge management solutions. 